\title{
Educadores en instituciones correccionales para jóvenes en Puerto Rico: Retos y necesidades de desarrollo profesional
}

\author{
Educators in Puerto Rican Juvenile Correctional Institutions: Challenges and Professional \\ Development Needs
}

\author{
Adalberto Santa Olmeda \\ Departamento de Educación, Gobierno de Puerto Rico \\ San Juan, Puerto Rico \\ santaadalberto@hotmail.com \\ Ángel A. Villafañe Santiago ${ }^{2}$ \\ Universidad de Puerto Rico, Recinto de Río Piedras \\ San Juan, Puerto Rico \\ angelpr39@gmail.com \\ Manuel Capella Casellas ${ }^{3}$ \\ Universidad Politécnica de Puerto Rico \\ San Juan, Puerto Rico \\ capella.manuel@gmail.com
}

1 Doctorado en Educación con concentración en Administración Educativa de la Universidad Interamericana de Puerto Rico y maestría en Investigación y Evaluación Educativa de la Universidad de Puerto Rico. Bachillerato en Educación en Ciencia General, Biología y Matemáticas de la Universidad de Puerto Rico. En cuanto a su experiencia laboral se destacó como especialista en investigaciones docentes, director de escuelas, maestro bibliotecario, coordinador de evaluación y maestro de ciencias. Toda su carrera profesional la realizó en el Departamento de Educación del Gobierno de Puerto Rico. Dicta conferencias a nivel nacional e internacional y es reconocido por su compromiso con sus supervisados y con los estudiantes. Actualmente labora en una propuesta llamada ZONE PRESS del Departamento de Recreación y Deportes del Gobierno de Puerto Rico coordinando servicios socioeducativos para comunidades pobres.

2 Doctorado en Educación con concentración en Consejería de la Universidad Interamericana de Puerto Rico y maestría en Consejería en Rehabilitación de la Universidad de Puerto Rico. Bachillerato en Artes con concentración en Trabajo Social de la Universidad Central de Bayamón, Puerto Rico; certificación en Evaluación Vocacional de la Universidad Interamericana de Puerto Rico y certificación en Asistencia Tecnológica del Instituto Fillius de la Universidad de Puerto Rico. Catedrático asociado del Departamento de Consejería para el Desarrollo Estudiantil (DCODE) de la Universidad de Puerto Rico. Investigador en el área de la violencia de género y otros temas. Publicaciones sobre violencia intrafamiliar, VIH/SIDA, hijos adultos de padres/madres alcohólicos (HADA), estudiantes internacionales y asistencia tecnológica, entre otros. Experiencia dictando cursos graduados y subgraduados relacionados a la conducta humana. Miembro de la Junta Examinadora de Consejeros en Rehabilitación de Puerto Rico del Departamento de Salud (JECR), del Comité de Investigación para la Seguridad del Sujeto Humano en la Investigación y del Colegio de los Profesionales de la Consejería en Rehabilitación. Premio ACER a la Excelencia Profesional (1994) y Mary E. Switzer (2007), otorgado por la Asociación Puertorriqueña de Rehabilitación, Puerto Rico.

3 Doctorado en Educación con concentración en Administración Educativa de la Universidad Interamericana de Puedo Rico y maestría en Investigación y Evaluación Educativa de la Universidad de Puerto Rico. Bachillerato en Ciencias con concentración en Biologia General de la Universidad de Puerto Rico. Actualmente es catedrático asociado del Departamento de Ciencias y Matemáticas de la Universidad Politécnica de Puerto Rico. Además, trabaja como investigador y evaluador pedagógico de programas, servicios educativos y otros asuntos relacionados. Sus publicaciones incluyen diversos temas como la violencia de género, la colaboración y las alianzas, sobre programas educativos financiados por fondos federales y creación literaria (poesía, cuento, ensayo), entre otros. Posee experiencia dictando cursos subgraduados en pedagogía, la enseñanza de las ciencias y las matemáticas y mentoría metodológica en el desarrollo de proyectos de investigación en acción. Ex militar con rango de Teniente Primero del Ejército de los Estados Unidos de América. 
Resumen. El propósito principal de la investigación fue conocer las experiencias vividas por docentes en las instituciones correccionales para jóvenes, sus retos y las necesidades de desarrollo profesional. La investigación que se realizó fue cualitativa, descriptiva, fundamentada en el enfoque fenomenológico, a través de una entrevista semiestructurada aplicada a cuatro maestros de la Administración de Instituciones Juveniles (AIJ) en Puerto Rico. La información fue analizada de acuerdo con los procedimientos sistemáticos de la investigación cualitativa sugeridos por Strauss y Corbin (1998), citados por Lucca y Berríos (2003): selección abierta, axial y selectiva, respectivamente. Se encontró que estos docentes presentaron grandes satisfacciones por prestar servicios educativos. Como aspecto relevante, se carece de un currículo que se amolde a las necesidades de la población juvenil atendida. El currículo utilizado en el programa educativo es el mismo que se ofrece en las escuelas públicas, por lo que no es atractivo para estos jóvenes. El personal docente confronta retos extraordinarios, desde el sistema de seguridad de las instituciones, hasta la metodología de la enseñanza y aprendizaje. Se percibe una ausencia en la coordinación de servicios educativos y el equipo multidisciplinario para atender los aspectos cognitivos y emocionales de los jóvenes. Al igual que los maestros de cualquier sistema educativo, los entrevistados obtienen unos logros y satisfacciones que los fortalecen espiritualmente y hacen que estos permanezcan muchos años trabajando en estas instituciones.

Palabras claves. Desarrollo profesional, experiencias vividas, instituciones correccionales.

Abstract. The main purpose of the present research was to report the experiences of teachers in juvenile correctional institutions, their challenges, and professional development needs. Research was conducted using a qualitative descriptive phenomenological methodology through a semi-structured interview applied to four teachers from the Juvenile Correctional Institutions Administration (AIJ) in Puerto Rico. The information was analyzed based on the systematic qualitative research procedures proposed by Strauss and Corbin (1998), cited by Lucca and Berríos (2003): open, axial and selective coding, respectively. Teachers were greatly satisfied for providing educational services. A relevant finding is the lack of a curriculum that fits the needs of this youth population. The curriculum used is the same as the one used in public schools, which makes it unappealing to these students. These teachers face unusual challenges, including the institutions' security system and the teaching and learning methodology. A lack of coordination is perceived in the educational services and a multidisciplinary team is needed to address the cognitive and emotional aspects of the population. Like teachers in any other educational system, respondents obtain some achievements and satisfactions that strengthen them spiritually and motivate them to continue working in these institutions for many years.

Keywords. Professional development, life experiences, correctional institutions.

La escuela se presenta como la institución que prepara a las personas para su adaptación armoniosa y efectiva a la vida social de un país (Bruner, 2001; Rivera, 2004). Ella contribuye a conservar y mantener la estabilidad y el orden del funcionamiento social, al moldear la personalidad individual según las normas sociales aceptadas. La escuela es la institución socializante de mayor congruencia con el sistema de valores y expectativas de nuestra sociedad. Constantemente cambia debido a la aplicación de la tecnología (Drucker, 1993). Por lo anterior, los maestros de cualquier sistema educativo se enfrentan a una sociedad 
cada vez más compleja. Educar para responder a los retos que acompañan esos cambios es la responsabilidad primordial de los sistemas educativos (Ramos y Bravo, 2002). Dado que el docente es agente motivador de la productividad estudiantil, se hace necesario transferir esta conciencia a los maestros y maestras de la Administración de Instituciones Juveniles (AIJ).

La AIJ es una agencia del gobierno de Puerto Rico, cuyo deber y responsabilidad es prestar servicios de evaluación, diagnóstico, rehabilitación y custodia a los menores intervenidos por el Tribunal de Menores. Todo menor custodiado por la AIJ participará de un programa encaminado a obtener el diploma de cuarto año. A algunos se les enseñan las destrezas básicas que le permiten la promoción a un grado escolar acorde con su edad cronológica. Estos servicios se complementan con educación ocupacional, educación especial (EE) y recreación. Los principales ofrecimientos son: servicios de educación remediativa en español, inglés y matemática y educación física. Para aquellos jóvenes mayores de 16 años se ofrecen servicios de educación de adultos conducentes a tomar el examen equivalente para el cuarto año de escuela superior.

Estos trasgresores de la ley, en su mayoría, provienen de hogares disfuncionales y son usuarios de drogas. Existe entre ellos una amplitud de niveles académicos, con problemas de aprendizaje y de salud mental. Son los maestros los que tienen más contacto directo con el joven trasgresor, y conocen sus características, motivaciones y condiciones en que estos se desenvuelven. Además, le proveen el afecto que tanto necesita este tipo de población. Según lo explicado por C. Alverio y P. Leoni (comunicaciones personales, 26 y 28 de septiembre, 2006), respectivamente, esta situación en las instituciones juveniles representa un reto y preocupación diaria.

\section{Marco conceptual}

La educación pública actual en Puerto Rico se fundamenta en la teoría cognoscitivohumanista y constructivista. De ella surgen los supuestos que rigen el diseño, producción, utilización, evaluación y desarrollo de los recursos (Ley Núm. 68, Ley Orgánica para el Departamento de Educación del Estado Libre Asociado de Puerto Rico, 1990; Rosado, 2001).

Tanto Piaget como Vigostky postularon sobre la construcción del conocimiento e indicaron que el desarrollo cognitivo es uno complejo, pues es más que la mera adquisición de información. El constructivismo como perspectiva epistemológica y psicológica propone que las personas formen o construyan su conocimiento, influenciado por la interacción de las personas con su entorno en el proceso de adquirir y refinar destrezas y conocimientos (Bruner, 2001). Esta teoría describe al aprendizaje como un proceso activo en el que los educandos construyen nuevas ideas o conceptos utilizando el conocimiento pasado y presente. De acuerdo a cómo seleccionen y transformen la información, construyan hipótesis y hagan la toma de decisiones, estructuran su desarrollo cognitivo, basado en esquemas y modelos mentales. 
URL: http://www.una.ac.cr/educare

CORREO: educare@una.cr

En Puerto Rico, ya De Hostos (1969) había establecido que el sistema de enseñanza debe buscar logros verdaderos en el educando y que no se puede limitar únicamente al cultivo del conocimiento; debe desarrollar el uso de la sensibilidad y de la voluntad. Esto implica que la educación tiene como fin primordial liberar la razón y el entendimiento de los educandos, y se debe organizar en orden lógico y psicológico, para educar la razón y formar el ser humano completo.

Freire (1987) fue consciente de que la sociedad que le tocó vivir poseía una dinámica estructural que conducía a la dominación de las conciencias, lo que se traducía en una pedagogía que respondía a los intereses de las clases dominantes. Los métodos que esta pedagogía utilizaba no podían servir a la liberación de los oprimidos, sino que más bien pretendían impartir entre estos la ley del temor.

La pedagogía del oprimido, como pedagogía humanista y liberadora tendrá, pues, dos momentos distintos aunque interrelacionados. El primero, en el cual los oprimidos van desvelando el mundo de la opresión y se van comprometiendo, en la praxis, con su transformación, y, el segundo, en que, una vez transformada la realidad opresora, esta pedagogía deja de ser del oprimido y pasa a ser la pedagogía de los hombres en proceso de permanente liberación. (p. 107)

Estos modelos de concienciación, del desarrollo de la razón, la moral y el ser humano completo, tienen sus bases humanistas que ayudan a entender los procesos cognitivos por los que pasan las personas. Al unir el cognoscitivismo y el humanismo se entrelazan nociones sobre la adquisición del conocimiento y del ser humano, como sujeto y objeto de su propio desarrollo. Dado esto, el fundamento teórico está centrado en la evolución del ser, tanto en su plano intelectual como en el emocional afectivo.

Cónsono con lo anterior, Goleman (2000) definió a la inteligencia emocional (IE) como un conjunto de habilidades con las que el ser humano es capaz de motivarse y persistir frente a las decepciones, controlar el impulso y demorar la gratificación, regular el humor y evitar que los trastornos disminuyan la capacidad de pensar, mostrar interés, empatía y abrigar esperanzas. La teoría sobre IE abarca cinco competencias: el conocimiento de las propias emociones, el manejo de estas, la auto-motivación, el reconocimiento de las emociones en los demás y el trato de las relaciones interpersonales.

El Departamento de Educación de Puerto Rico (DEPR) idealiza la práctica profesional de los docentes. De acuerdo con esto y los teóricos presentados, se hizo necesario desarrollar un marco conceptual fenomenológico para enmarcar las actividades educativas que realizan los docentes en las correccionales juveniles. 
Diversos documentos publicados en EDJ Notes del Center for Education, Disability, and Juvenile Justice en Estados Unidos afirman que la educación es un componente efectivo en la rehabilitación y reintegración de los jóvenes transgresores a la comunidad. Por tal razón, los maestros que realizan el proceso de enseñanza y guían el aprendizaje contribuyen al proceso de rehabilitación. La forma más eficaz de contrarrestar una conducta problemática y ayudar en el aprendizaje de un comportamiento social aceptable es estrechando los lazos emocionales entre docente y alumnado. Por ello, P. Leoni, (comunicación personal, el 28 de septiembre, 2006) considera que para poder comprender y ayudar mejor al alumnado, el personal docente deberá relacionarse, hasta donde sea posible, con la vida misma de este, su medio ambiente y sus experiencias. Solo así podrá comprender la conducta y sus actitudes, incluyendo sus posibles motivaciones.

A través de una investigación cualitativa fenomenológica, Ragland (2005) describió las experiencias de trabajo de compañeros maestros en una institución juvenil. Este estudio evidenció que existen limitadas oportunidades para que los maestros o maestras puedan reunirse con otros miembros de la facultad. El desarrollo profesional se ve limitado por el tiempo disponible dentro de un calendario escolar de diez meses. Afirmó que los maestros sustitutos son difíciles de encontrar e imposibles de conservar. De igual forma, los maestros funcionan primero como oficiales de seguridad y luego como educadores. En resumen, allí no se había desarrollado un sentido de comunidad por la carencia de relaciones profesionales entre colegas.

Por su parte Sayko (2005), en otra investigación similar, encontró la lucha existente entre las fuerzas del castigo y la rehabilitación. Los maestros promovían la rehabilitación mientras los custodios creían en mantener el control y la seguridad en la institución. Ese escenario provocó desánimo personal, confusión, ambiente hostil, ambigüedad relacionada con la identidad profesional y aislamiento del personal docente. Además, los maestros señalaron que existía desinformación e ignorancia acerca de lo que es la educación correccional en las instituciones. La autora indicó que no se sentía preparada para entrar a trabajar como maestra en una institución correccional. Todos los maestros entrevistados indicaron que los estudiantes confinados poseían rezago académico y cultural, y consideraban un gran reto el ayudar en forma efectiva a esto jóvenes (dato que es consistente con lo encontrado por Gehring y Puffer, 2005).

Otros aspectos que obstaculizan la difícil tarea educativa en instituciones correccionales fueron descritos por Sauter (2000) y Carr (2001). Por ejemplo, hay poco acceso a la bibliografía del campo de la educación correccional, la cual pudiera ayudar a realizar la labor en una forma más efectiva. Además, la cultura organizacional de la prisión es muy política, lo cual provoca en el cuerpo docente una sensación de persecución; no se le da crédito al su profesionalismo y tampoco se respetan los códigos de ética.

\section{Desarrollo profesional del personal docente de las instituciones correccionales}

El desarrollo profesional de los educadores correccionales ha sido esporádica y pobremente definido. La preparación tradicional de los maestros enfatiza contenidos de conocimiento, 
que muy poco capacitan a las personas que trabajan en las instituciones correccionales para su labor profesional (Eggleston, 1991). En los programas tradicionales de preparación de maestros están ausentes los adiestramientos en manejo de conducta y coraje, y principios básicos de psicología (Jurich, Casper y Hull, 2001). Estos autores indicaron que hay necesidad de desarrollo profesional en términos de filosofía de la educación correccional, de destrezas de comunicación en un ambiente cerrado y el comportamiento humano criminal, el burn out, y de técnicas efectivas de enseñanza. Por su parte, Sauter (2000) encontró que el aislamiento de este personal le impide competir en la utilización de fondos federales; estar actualizados en estudios emergentes sobre temas de educación correccional y beneficiarse de actividades promovidas por organizaciones que satisfagan sus necesidades de desarrollo profesional.

Gehring y Hollingsworth (2002) sostuvieron que los maestros de las instituciones correccionales sufren constantemente de burn out y de una serie de problemas especiales exclusivos de su profesión. Ellos detallaron muchos riesgos y el bajo salario. Además, estos profesionales atienden estudiantes en desventaja académica y económica, dentro de un ambiente depresivo e inhumano, en el cual el programa educativo no tiene ninguna importancia para el resto del personal institucional. Como agravante, el programa educativo correccional tiende a ser pobremente planificado e implantado, y raras veces evaluado sistemáticamente.

En resumen, los educadores correccionales presentan necesidades específicas de desarrollo profesional. Este personal se encuentra en aislamiento, desconoce los fundamentos filosóficos de la educación correccional, y tiene acceso limitado a las publicaciones profesionales relacionadas con su profesión. Todo esto contribuye a la falta de identidad en la profesión.

\section{Retos de los maestros de las instituciones correccionales}

La visión de la educación, sea general o de las instituciones correccionales, es producir cambios en conducta. Sin embargo, en las instituciones correccionales el personal de custodia ofrece muy poco apoyo al programa educativo. Esto crea cierta hostilidad de parte de este personal hacia el programa educativo (Geraci, 2002; Sayko, 2005).

Disponer de servicios de calidad en la educación correccional es importante para la transición efectiva de estos jóvenes a la sociedad. La educación correccional puede ser la última oportunidad de estos jóvenes para adquirir destrezas académicas y ocupacionales (Foley, 2001). Esto reclama que los maestros de las instituciones correccionales estén debidamente preparados para atender las necesidades reales de esta población para que puedan reincorporarse a la sociedad en forma productiva (C. Alverio y P. Leoni, en comunicación personal el 26 y 28 de septiembre de 2006, respectivamente).

Desafortunadamente entre el $12 \%$ y el $60 \%$ de los jóvenes ofensores tienen problemas de aprendizaje (Wolford, 2000; Dean, 2005) y la mayoría son de educación especial (Dean, 2005; P. Leoni (comunicación personal, 28 septiembre, 2006). Foley (2001) entiende que estos jóvenes parecen tener mayor dificultad en regresar a la escuela regular, 
luego de su excarcelación. Estas situaciones aparentemente provocan que estos jóvenes ofensores experimenten un alto grado de reincidencia contrario a otros encarcelados sin impedimentos (Black et al., 1996).

Los hogares de detención, diferentes a las correccionales juveniles, proveen cuidado a corto plazo, en lo que sus custodios legales atienden diferentes aspectos relacionados a custodia y responsabilidad jurídica. La edad promedio de los ofensores fluctúa entre los 7 a 18 años. Estos hogares deben proveer servicios de educación, por lo cual tienen sus propios programas escolares. Según lo observado por Weis, Haynes y Lloyd (2001), un 17\% de los trasgresores participaban de un programa de educación especial, el 50\% no asistían a sus clases y el $62 \%$ de los que asistían a las clases regularmente funcionaban bajo el nivel del grado académico. En cuanto a las condiciones de trabajo en la institución, los maestros tenían en ocasiones siete preparaciones diferentes. Los encuestados indicaron que necesitan ser adiestrados para enseñar a estos jóvenes y manejar adecuadamente la conducta basada en una instrucción programada e individualizada.

La mayor parte de los maestros no aspiran de primera instancia enseñar en la prisión. Muchos de ellos llegan a estos centros por casualidad, incidentalmente o quizás como parte de preservicios de algún programa de desarrollo profesional (Geraci, 2002; Wright, 2005). Aprender a enseñar en este escenario es peligroso, frustrante, confuso, inquietante y perturbador. Los maestros de nuevo ingreso consideran que enseñar en este escenario es una experiencia totalmente diferente de lo aprendido en la universidad (Wright, 2005). Aquellos maestros que se inician en las instituciones correccionales experimentan un shock cultural (Geraci, 2002; Jandt, 2004). Por estas razones, es necesario disponer de un adiestramiento en preservicio sobre enseñar en las correccionales, de modo que los apreste a conocer la cultura organizacional de estas instituciones.

Drucker (1993) planteó que la globalización ha cambiado de una economía industrial y manufacturera hacia aquella que es tecnológica y de servicios. Considera que el conocimiento y la información son los nuevos recursos estratégicos económicos, y que estos cambios sugieren que los trabajadores deben desarrollar mejores destrezas de pensamiento crítico y solución de problemas. El trabajo más simple y rutinario requerirá altas destrezas de pensamiento. Se espera que los trabajadores piensen en forma abstracta, crítica y cuantitativa; que sepan organizar la información y puedan trabajar en forma cooperativa con otros. Ante estas demandas, todo currículo debe considerar como fundamento la economía del conocimiento y ha de estar centrado en cuatro áreas: construcción del conocimiento, auto regulación del aprendizaje, conexión con el conocimiento existente y comunidades de aprendizaje (Price, 1996).

En síntesis, los maestros de las instituciones correccionales reciben la misma preparación universitaria que sus colegas de escuelas públicas o privadas. La educación correccional es una carrera especializada que requiere de profesionales educativos muy bien adiestrados para atender a una clientela heterogénea y con necesidades académicas específicas. Por todo 
URL: http://www.una.ac.cr/educare

CORREO: educare@una.cr

lo anterior, en Puerto Rico era necesario conocer la realidad educativa en las correccionales juveniles. Esos datos pueden ayudar a los administradores a establecer programas educativos efectivos. La implementación de estos debe promover la rehabilitación de los jóvenes transgresores y facilitar su reintegración a la comunidad.

\section{Metodología}

\section{Población y selección de los participantes}

Los participantes de este estudio fueron los maestros de las instituciones correccionales para jóvenes de Puerto Rico. Los criterios de inclusión para seleccionar los participantes fueron: ser mayor de edad (21 años o más), con diez años o más enseñando en cualquier institución juvenil pública en Puerto Rico (centro de detención; centro de tratamiento; campamento u hogar de grupo) y que su disponibilidad para participar en el estudio fuese libre y voluntaria. Se escogieron cuatro maestros que poseían la mayor cantidad de años en servicio.

\section{Diseño de investigación}

Luccay Berríos (2003) señalan que el uso de la metodología cualitativa en las investigaciones educativas y sociales han tenido un auge sin precedente en las últimas dos décadas de siglo XX. La investigación que se realizó fue cualitativa, descriptiva, fundamentada en el enfoque fenomenológico. Se trabajó la investigación a través de una entrevista semi-estructurada. Tres áreas fueron estudiadas: experiencias vividas de los maestros de AlJ, retos que enfrenta el docente diariamente para llevar a cabo su labor con el joven trasgresor y las necesidades de desarrollo profesional. Sin embargo, se dejó abierto el espacio para nuevas interrogantes que emergieran de los datos.

\section{Procedimiento}

En primer lugar, se solicitaron las debidas autorizaciones de las agencias, tales como: la Junta Institucional de Revisión (IRB) y la Administración de Instituciones Juveniles. Se anunció en las diferentes correccionales a través de cartelones y hojas sueltas en los tablones de edictos. Con los que respondieron a la solicitud, se concertó una cita inicial para explicarles el proyecto $y$, en esta, ellos tuvieron la oportunidad de expresarse sin ningún tipo de presión indebida. Finalizada la orientación y una vez que aceptaron participar, completaron la Hoja de Consentimiento Informado. Cada entrevista fue grabada en audio, transcrita ad verbatim y, luego, la información fue analizada de acuerdo con los procedimientos sistemáticos de la investigación cualitativa sugeridos por Strauss y Corbin (1998), citados por Lucca y Berríos (2003). 
Se enumeraron las transcripciones desde el uno hasta el cuatro, con el fin de cuidar los asuntos de confidencialidad y poderlos identificar en el proceso de la redacción de los hallazgos. Con una lectura minuciosa de las respuestas, guiada por el audio correspondiente, se verificó la transcripción ad verbatim. En otra lectura, se identificaron aquellos fragmentos que contenían información relevante (selección abierta). Por otro lado, se descartaron los fragmentos que resultaron ser poco relevantes. Luego, los fragmentos escogidos se agruparon por pregunta para refinar el proceso analítico. Lo seleccionado fue reclasificado en temas y patrones comunes, por ejemplo, el manejo de los jóvenes que tienen problemas de salud mental y de educación especial (EE); la preparación que debe tener un maestro que atiende jóvenes en instituciones juveniles, y los aspectos de seguridad intrínsecos al escenario laboral. Estos se codificaron según emergían y se establecieron posibles conexiones entre los temas (codificación axial). Finalmente, la codificación selectiva se enfocó en la integración de las categorías medulares para explicar la amplitud y diversidad de los aspectos estudiados.

Tabla 1

Codificación selectiva: Las experiencias vividas de los maestros de AIJ

\begin{tabular}{ll}
\hline Categorías & Propiedades \\
\hline Significado adscrito a la experiencia vivida & Toma de decisión de trabajar en AIJ \\
& $\begin{array}{l}\text { Escenario de trabajo } \\
\text { Estar en una institución correccional } \\
\text { El registro rutinario }\end{array}$ \\
& La preparación del maestro en la institución \\
& La vivencia de ser maestro \\
& El diario vivir en el salón de clase \\
& El joven en AIJ \\
Visión general & Con problemas de salud mental \\
Los jóvenes de educación especial & \\
El aspecto espiritual del maestro & \\
Logros del maestro con los jóvenes
\end{tabular}

\section{Hallazgos}

Para describir las experiencias vividas de los participantes de esta investigación, las necesidades que confrontan comúnmente como parte de su labor profesional en este peculiar ambiente educativo y sus significados, se creó un diagrama lógico conceptualizado basado en la codificación selectiva de la información (Creswell, 1994). En la Tabla 1 se aúnan los hallazgos 
URL: http://www.una.ac.cr/educare

CORREO: educare@una.cr

en dos categorías: significado adscrito a la vivencia del maestro de AIJ y los aspectos sobresalientes de la experiencia. Como subcategoría del significado adscrito a la vivencia, el proceso de la toma de decisión para trabajar en una institución juvenil emergió como un aspecto medular, cuya influencia impactó la motivación y la fortaleza para lidiar con los vaivenes laborales. Cinco subcategorías se identificaron para describir la experiencia del maestro. En la subcategoría escenario de trabajo se identificaron dos propiedades, el estar en una institución juvenil y los registros que se realizan como condición de la seguridad institucional. La preparación del maestro y las características del joven que están bajo la custodia de AIJ son dos lados de una misma realidad. Para entender esta dicotomía, se profundizó en las características del joven tanto en forma general como en aquellos que padecen de alguna condición de salud mental. Por último, se incluyen las subcategorías sobre el diario vivir en el salón de clase, los jóvenes con condiciones especiales y el aspecto espiritual de los maestros.

\section{Significado adscrito a la experiencia vivida de los maestros en AIJ}

El tipo de tratamiento que está recibiendo el joven trasgresor en AlJ está basado en la represión y medidas punitivas, y no en un método curativo eficaz y humano. Es decir, la educación del joven trasgresor no responde a su desarrollo completo como persona.

\section{Respecto a la toma de decisión de trabajar en AIJ}

El programa educativo de la AIJ utiliza los currículos, normas y manuales de procedimientos del Departamento de Educación de Puerto Rico (DEPR). La preparación académica de los maestros que enseñan a los jóvenes ofensores es la misma que la de sus colegas en el sistema público o privado. A continuación, algunos comentarios sobre la decisión de trabajar en AIJ.

Al trabajar con niños con impedimentos, me interesé en atender las poblaciones en desventaja. Cuando me gradué de bachillerato surgió la oportunidad de trabajar en una institución correccional en un puesto relacionado a ofrecer servicios auxiliares a los jóvenes. Al cabo de un tiempo de comenzar en la institución, surgió la oportunidad de trabajar como maestro. Fue fácil para mí aceptar la posición, porque tenía experiencia previa con este tipo de población. (Participante 1)

Una persona que trabajaba en la [nombre de la institución], me indicó que fuera a solicitar el puesto de maestro que él pensaba dejar. Y así fue ... Solicité y me dijeron que sí. Todos los años solicitada al DE ... pero era para cubrir plazas de periodos cortos de tiempo, por ejemplo, licencia de maternidad o enfermedad. Por tal razón no aceptaba y continué en AlJ. (Participante 2) 
Cuando estaba estudiando la maestría en la universidad, me enteré en la Oficina de Empleo que había una plaza de ayudante de maestro en [nombre de la institución]. Fui a entrevista y acepté, sin importar la clientela que iba a atender. Este era mi primer trabajo y no interrnalicé [sic] el tipo de jóvenes que iba a atender. Al cabo de un tiempo pasé de la posición de ayudante de maestro a maestro [regular]. En ninguna de las dos posiciones ocupadas en AlJ he sentido miedo. (Participante 3)

Una persona que trabajaba en [nombre de la institución] me informó que existía una plaza de maestro y me recomendó. Como yo había estudiado el bachillerato en educación y no estaba trabajando, me entrevistaron y fui seleccionado. Inmediatamente comencé a trabajar y no me arrepiento, llevo unos cuantos años en AIJ. (Participante 4)

Como se puede apreciar, algunas personas entran a trabajar a una institución porque quieren cambiar de trabajo. Otros por interés genuino de ayudar y hacer la diferencia con esta población o, sencillamente, por obtener un trabajo (Sauter, 2000). De acuerdo con Sauter y C. Alverio (comunicación personal, 26 de septiembre, 2006) los que solicitan trabajar como maestros en las instituciones juveniles provienen de diferentes áreas profesionales, con una diversidad de conocimientos y preparaciones, pero no son educadores certificados. Casualmente, todos los maestros entrevistados estaban recién graduados al momento de solicitar y ser aceptados dentro del sistema correccional. Ellos coincidieron en que esta fue una oportunidad de trabajo y decidieron aprovecharla. Destaca el hecho de que los participantes decidieran trabajar en AIJ tras no haber ofertas en el DEPR. Por esas razones, se puede entender que algunos no desarrollen un sentido de pertenencia, salvo aquellos con alguna experiencia previa trabajando en una correccional.

Trabajar en una correccional y permanecer por varios años allí es una cantera de experiencias vividas. Cada experiencia es única y merece ser estudiada.

\section{La experiencia del maestro en AIJ}

La educación correccional en Puerto Rico es un tema del que se sabe muy poco. Cuando se comenta sobre ella resaltan las revueltas y motines que ocurren y, muy poco, se divulga la labor positiva que allí se realiza. Se hacen esfuerzos no estructurados para que la educación correccional sea aceptada como disciplina profesional. Al momento, en Puerto Rico no existe una organización que represente a estos educadores, tenga la intención de mejorar sus condiciones de trabajo y defienda sus intereses y filosofía.

El estar en una institución correccional presenta una serie de retos. Por ejemplo, estas instituciones tienden a estar localizadas en lugares remotos o áreas rurales de difícil acceso. El 
URL: http://www.una.ac.cr/educare

CORREO: educare@una.cr

nivel de peligrosidad de la población requiere de medidas de seguridad para entrar, permanecer y salir. El solo hecho de estar allí produce en todo el personal cierta tensión, particularmente en los maestros. El ambiente en las instituciones juveniles, al igual que en las de adultos, es muy restrictivo y represivo. A continuación algunos datos sobre el estar en este lugar.

En la universidad aprendí mucho de la materia que enseño, a hacer un plan de enseñanza y ejecutarlo pero cómo enseñar y tratar jóvenes institucionalizados, eso lo he aprendido en las mismas instituciones ... No ha sido fácil. (Participante 1)

Cuando comencé a trabajar en AIJ, pensé en tomar algún curso que ayudara en este escenario, pero pensé, en la universidad no recuerdo haber visto algún curso relacionado a cárceles o jóvenes que están bajo la custodia del estado. (Participante 2)

El maestro que trabaja en instituciones juveniles debe ser especial, porque esta población también es especial. En algunos casos creo, que estos jóvenes están bien, porque al conocer su pasado, es decir, [en] su infancia han sufrido mucho. Por eso ... requieren un trato especial ... necesitan mucha motivación. A mí me ayudó mucho la orientación que recibí de los compañeros maestros. (Participante 3)

A los maestros de las instituciones juveniles deben darles unos cursos especiales sobre cómo manejar a estos jóvenes. (Participante 4)

El control y la seguridad son dos aspectos claves para el funcionamiento apropiado de cualquier institución correccional. Una situación, por pequeña e insignificante que sea, puede causar graves incidentes y confrontaciones entre la población penal. Los jóvenes reclusos tienen muchas vivencias de la calle y llegan a ser muy manipuladores (Geraci, 2002). Cualquier acto de bondad mostrado a los reclusos por parte del personal es visto erróneamente como una debilidad (Sauter, 2000). Por tal razón, mostrarse muy amigable, familiar o bondadoso con los reclusos no es permitido en muchas de las facilidades correccionales. Estos aspectos se observan a través de los comentarios de los maestros entrevistados.

La gente siempre dice que los presos son malos, ... al momento de entrar a la institución sentí un poco de miedo ... En realidad [experimenté] preocupación, nunca había trabajado con niños en custodia. Desde el primer día me di cuenta que esos jóvenes necesitaban de mí. (Participante 1) 
A mí me dijeron que eran jóvenes transgresores...que tenían que cumplir unas medidas dentro de las instituciones, y por ser menores había que ofrecerles los servicios educativos [según] exigía el Departamento de Educación. Me dijeron los compañeros maestros que mantuviera distancia y categoría y que no dejara nada mal puesto en el salón, porque podía desaparecer. (Participante 2)

No me ofrecieron información concreta de la población [penal] ... de máxima seguridad que iba a atender ... Cuando comencé a trabajar en la institución, los compañeros maestros me pintaron la misma como el cuco (refiérase en la lexicografía puertorriqueña y mitología popular a un ente androgénico que inspira terror) ... Los grupos [de estudiantes] eran [descritos] fuertes. [Como hábito] tenía que vestir ropa bastante cubierta y que no dejara nada a la vista de los muchachos. (Participante 3)

Cuando llegué a la institución, el director me paseó por toda la institución y me indicó lo bueno de la institución y también ... todo lo feo. Me mostró lo que era una figa [objeto cortante en forma de navaja] y dijo que había que tener mucha precaución ... y mucho valor para trabajar en una institución juvenil. Yo tenía un familiar que trabajaba aquí, y me orientó ... sobre ... los motines, de cómo tomar las debidas precauciones. A la verdad que estamos teniendo difícil reclutamiento en esta área geográfica, porque algunos maestros llegan a la institución y renuncian rápido. Cuando baja toda la matrícula al área escolar no me siento que exista seguridad. Esta institución es nivel cinco y tiene una capacidad para 120 jóvenes. En ocasiones están 90 o más jóvenes en el área escolar, con solo siete custodios. En esos momentos no he sentido seguridad. En una ocasión fui rehén. (Participante 4)

De acuerdo con lo expresado, la información que se les provee al momento de las entrevista de trabajo es mínima. Se ofrece poca información de lo que es una institución correccional y de las características de la población que en ella se atiende. Es imperioso señalar que, en el caso particular de la AIJ, toda la información referente a los jóvenes y sus trasgresiones es completamente confidencial, por la condición de minoría de edad.

A pesar de los miedos que algunos de los entrevistados indicaron tener en algún momento al principio de su labor, también es cierto que han sentido un gran placer de servir a esta población. Dos maestros plantearon que la orientación que les dieron sus colegas y los administradores fue valiosa, particularmente durante sus primeros días en la institución.

Yo te diría que los maestros son los más que conocen la matricula, más que la directora escolar. Son los que están allí, día a día con el joven. Por eso digo que la verdadera orientación fue de los compañeros maestros. (Participante 4) 
URL: http://www.una.ac.cr/educare

CORREO: educare@una.cr

A los maestros entrevistados se les preguntó sobre la utilización de algún Manual de procedimientos que tratase sobre lo que es una institución juvenil, las características de los jóvenes y otros señalamientos que se deben observar en una institución correccional. En términos generales, ellos no recordaban si existía tal documento y afirmaron no haber recibido algún material relacionado al momento de comenzar a trabajar como maestro correccional.

El registro rutinario. Esta es una de las políticas obligatorias para mantener el orden, el control y la seguridad de todos allí. Este registro se aplica a todo el personal que entra y sale de cualquier institución correccional. En relación con este proceso institucional, los maestros indicaron lo siguiente.

La primera vez que entré a [nombre de la institución], una persona me registró, me cateó y me tocó las partes íntimas. ¡Qué horrible es eso! Sentí ansiedad e incomodidad y todavía perdura en mí esa sensación. (Participante 1)

Se chequea por encima de la ropa. Unas instituciones exigen más seguridad que otras. Las carteras de las maestras no entran al área escolar, se dejan en el baúl del carro o en un locker ... No me molesta el registro. (Participante 2)

En el registro diario, el custodio me revisa mis pertenencias y no me deja entrar el periódico EI Vocero [pero sí] el periódico EI Nuevo Día ... con cierta reserva porque le digo que es para [usarlo como recurso en la clase]. No molesta que me registren. (Participante 3)

Caramba, depende de cómo esté mi estado de ánimo, porque somos seres humanos ... sé que ellos tienen que cumplir con su labor de registro, pero muchas veces incomoda ... incomoda. (Participante 4)

El registro previene la introducción de drogas y otros materiales ilícitos a las instituciones. Puede ser incómodo en ocasiones, pero eventualmente se convierte en una actividad rutinaria que algunos superan. En otros pueden permanecer las reacciones adversas.

La preparación académica del maestro de AIJ. Los maestros de las correccionales carecen de la preparación adecuada para atender esa población particular de aprendices (Sauter, 2000; P. Leoni (comunicación personal, 28 de septiembre, 2006). Por lo general son educadores 
para poblaciones regulares, en las que la heterogeneidad incluye diferentes trasfondos socioeconómicos, etnias, educación especializada, entre otros. De acuerdo con los entrevistados Alverio y Leoni (2006), los programas de formación de maestros en las universidades del país no proveen experiencias ni exposición a la enseñanza en los sistemas correccionales. Tampoco se ofrecen adiestramientos especializados para trabajar en escenarios atípicos, diferentes a los que se dan comúnmente en nuestros centros escolares públicos o privados.

Este escenario queda reflejado en algunos comentarios extraídos de las entrevistas. Según estos, se reciben orientaciones generales por parte de los directores administrativos o escolares de las instituciones. Esta orientación es acompañada por lo regular de una visita en forma rápida y general a las áreas de servicios de la institución.

La preparación de maestro que adquirí en la universidad me ha ayudado [para enseñar] lo que estoy enseñando,... No recuerdo alguna clase o práctica de [campo sobre] enseñanza a jóvenes delincuentes... El manejo de estos jóvenes lo aprendí aquí. (Participante 1)

La enseñanza es casi la misma, tienes que utilizar las diferentes técnicas... porque el muchacho es casi el mismo que el que está afuera. ... Es cuestión de uno, cómo buscarle la vuelta y llegar al estudiante. Con uno se llega de una manera; con otros se llega de otra. Pero, aquí aprendí a cómo manejar a estos jóvenes ... Estoy acostumbrada, te puedo decir que me hacen falta. (Participante 2)

En términos administrativos, lo que aprendí en la universidad me ayudó. Cómo se hace un plan, esto o lo otro ... Pero, como el maestro se hace en el salón de clases, se aprende en la marcha. Ahí es que el maestro se hace. Sí, los estudios, definitivamente en [cuanto a] lo administrativo y todo eso me ayudaron en cantidad. [Sin embargo], a saber sobre los diferentes estudiantes que uno tiene y cómo debe de tratarlos, eso lo aprendí aquí ... El maestro se hace en la marcha y en el salón de clase, atendiendo a los jóvenes. (Participante 3)

Se debe recibir una preparación diferente a los maestros de la escuela pública, porque esto es una matrícula muy especial con muchas problemáticas. Creo que se debe preparar unas clases especiales para los maestros de instituciones juveniles que traten sobre el manejo de estos jóvenes, porque...son muy diferentes. (Participante 4)

La educación correccional es una ocupación especializada, la cual requiere de maestros debidamente capacitados. Al presente, en Puerto Rico, la preparación y requerimiento de certificación de los maestros de las escuelas pública y de las instituciones correccionales son 
URL: http://www.una.ac.cr/educare

CORREO: educare@una.cr

exactamente los mismos, aunque sean dos poblaciones muy diferentes entre sí. En ocasiones se tienen a maestros trabajando en las correccionales que no poseen ninguna preparación en pedagogía Sauter, 2000; P. Leoni (comunicación personal, 28 de septiembre, 2006). Estudiosos de la educación correccional en Estados Unidos argumentan que una preparación académica es necesaria para ejercer en las instituciones correccionales. Los maestros que participaron en el estudio reclaman un desarrollo profesional especializado para atender esta población. Sin embargo, indicaron que su preparación profesional como docentes les ayudó.

La vivencia de ser maestro en una correccional juvenil. Para cada entrevistado, ser maestro de una institución juvenil es una experiencia diferente. Sin embargo, ellos señalaron algunas habilidades y destrezas especiales que se deben poseer para tratar a estos jóvenes.

Es algo gratificante, aunque tal vez no todo el mundo lo piense de esta forma. Aquí el maestro tiene la oportunidad de tener acceso a [conocer detalles] estudiante más que ningún otro personal de la institución. (Participante 1)

Con [estos] jóvenes hay que saber ser de todo un poco ... maestro ... padre y madre; todo [aquello] que [ayude al] menor, para que pueda ... apreciar la [educción que recibe]. (Participante 2)

No es solo ser maestro, hay que ir más allá de lo que se enseña ... Uno tiene que ejercer ... de enfermero, psicólogo, padre/madre, amigo ... Es importante no dejarse vencer fácilmente, esto no es color de rosa, es contra la corriente. ... Tanto papeleo ... con lo que muchas veces no se puede [cumplir cabalmente]. (Participante 3)

Un buen maestro [aquí] se debe dar por entero. Repito es especial. [Lo] tiene que ser especial para trabajar en un lugar como este ... Deben tener unos adiestramientos diferentes a los maestros de las escuelas públicas. (Participante 4)

Los entrevistados coincidieron en algunos aspectos sobre lo que recuerdan como su primera experiencia docente en este tipo de escenario. Tres de ellos coincidieron en que ser maestro correccional requiere realizar otras tareas que trascienden sus obligaciones magisteriales. Un participante indicó tener otros adiestramientos a los que reciben los maestros de las escuelas públicas. Ningún maestro manifestó miedo al trabajar con esta clientela. Revisemos algunos de sus comentarios. 
Mi primera experiencia...fue en una institución de mínima seguridad. [Ahora] estoy en una institución con [una] seguridad más estricta. [Aquí] me molesta el registro diario ... y el ruido al cerrar y abrir las puertas al área escolar. (Participante 1)

Desde el principio que entré a la institución me gustó. De hecho, muchas personas me [preguntaron] si sentía temor y les decía que trabajaba con mucha seguridad;... siempre teníamos unos custodios que estaban pendientes. [Nada] de miedo, ni temor. (Participante 2)

Al [empezar] no asimilé la clase de muchachos que iba a atender. Sentí como si fuera para una escuela [regular] ... No he sentido miedo. Este trabajo lo he visto como uno más; el primero como maestra ... Y fue un reto. Años atrás, los niños eran más tranquilos, respetuosos, contrario a los de ahora. (Participante 3)

Puedo confesar que tuve mis temores, pero al ver a otras personas, que eran más o menos de mi misma edad, [pensé que] si ellos pueden, pues yo [también] ... Este trabajo ... es fuerte; los jóvenes de hoy no son los mismos que hace unos años ... demandan más de uno. (Participante 4)

Todos los maestros entrevistados tienen más de 15 años enseñando en AlJ y tres de ellos eran mujeres. Además, todos indicaron que su experiencia ha sido buena o muy buena.

[La experiencia] ha sido muy buena ... bien gratificante, porque por lo menos hay jóvenes que han aprendido. [Los he encontrado en la libre comunidad] y me indican que aprendieron mucho de mí ... Puede que sea un poquito molestoso ser maestro en AIJ, pero siempre he tratado de ayudar al máximo a todos los estudiantes que pasan por mi [salón]. (Participante 1)

A mí me encanta [se ríe]. Siempre lo he disfrutado y he estado en varias instituciones ... Algún día tendré que retirarme. No sé cómo me sentiré cuando no los vea, creo que muy triste [se le salieron las lágrimas]. (Participante 2)

Muy buena, casi siempre gratificante, aunque a veces es frustrante. A veces ... ellos no tienen interés...y me frustro, jay Dios! Esos nenes no tienen interés en nada ... Puedo 
URL: http://www.una.ac.cr/educare

CORREO: educare@una.cr

afirmar que el que trabaja en AIJ puede trabajar en cualquier escenario, en cualquier escuela, puede entender a cualquiera. (Participante 3)

En general, el maestro [correccional] tiene que ser un ejemplo y modelo, en todos los aspectos. Desde [el primer momento] debe reconocer que está trabajando con un joven, pero que a la misma vez, tiene unas necesidades y limitaciones, [por ende] debe estar preparado en todos los aspectos. Su vestimenta debe de ser adecuada. Debe mantenerse y buscar la forma de prepararse continuamente. (Participante 4)

Estos comentarios denotan su complacencia ante el reto de trabajar con jóvenes institucionalizados. Conviene resaltar que el sistema de corrección se fortalece al contar con maestros experimentados con más de 15 años, esto es indicativo del sentido de pertenencia que sienten y por los lazos sentimentales que desarrollan con este tipo de población.

El diario vivir en el salón de clase varía entre los entrevistados. Sin embargo, hicieron hincapié en que ciertas situaciones se hacen rutinarias y siempre se vive en estado de alerta.

Por lo general yo tengo unas tareas específicas para los jóvenes cuando están en mi clase. Lo que hago dependiendo del tema, ofrezco el material, escrito o verbal. Luego, ofrezco una demostración, [y después] ellos [realizan algo] práctico. Ahí ellos desarrollan destrezas motoras que serán necesarias [para] el oficio [que aprenden]. Cuando es hora de marcharnos, todo el mundo tiene que recoger, limpiar y organizar el material ... Hay días que los jóvenes no están dispuestos a trabajar; todo depende del estado de ánimo. (Participante 1)

Los muchachos llegan saludando o relajando con los otros. Pero una vez uno le dice ubíquese, vamos a ver si nos sentamos, ellos [obedecen]. Puede ser que uno que otro continúe jugando de manos, pero se tranquilizan. Tengo que estar pendiente [a las] rencillas [y evitar] que entre ellos mismos se vallan a agredir...Contra el maestro no lo hacen. (Participante 2)

A veces cuando el menor recibe una noticia de su casa, viene más inquieto. En el salón de clase [ellos] se presentan con poco interés ... depende del ánimo de ese día. A veces siento frustración [pues] no les interesa lo que le enseño. A ellos les gusta lo visual y lo que sea diferente a lo que se enseñaba en sus [respectivas] escuelas públicas de procedencia. 
También influyen factores ambientales, el calor en el salón es horrible, a veces alcanza más de $100^{\circ}$ Fahrenheit. [En las] horas finales del día, [hay más] calor y hambre. Tengo que luchar más para que puedan entender y presten atención. Tengo que esforzarme más. (Participante 3)

Se pierde más [tiempo] orientando al menor que las mismas clases que se dan. A veces llegan con [ganas] de molestar y dicen: - ¡Hoy, no queremos clase y vamos a fastidiar toda la hora! A mí me [exigen] que el menor que moleste, tengo que dejarlo en el salón. Les pido que traten de mantenerse quietos y realicen la tarea del día y que me dejen trabajar con los que desean trabajar. Esta tarea es agotadora. (Participante 4)

En el salón, los maestros académicos pasan 50 minutos con el grupo de jóvenes y sus colegas de educación ocupacional los atienden por un periodo de 90 minutos. Algunas instituciones presentan condiciones ambientales que pueden ser catalogadas de infrahumanas. Otro reto que confrontan es la falta de interés de los jóvenes por aprender la tarea de cada día. Son muchas las estrategias a las que tiene que recurrir el docente para captar la atención y mantenerlos motivados.

A los jóvenes no les gusta lo tradicional, esto es, el libro y la pizarra. - Ay Missi, pero eso era lo que yo tenía en la escuela donde yo estaba. Cuando les traigo películas o algún recurso conferenciante, eso les encanta. Realizar este tipo de actividad no tradicional resulta muy difícil de coordinar y desarrollar en la institución. En ocasiones discutimos temas libres del periódico. La institución no provee el periódico y tratar de entrarlo al salón es peor. Los custodios son los primeros en decirte que no se pueden entrar. (Participante 3).

Cuando puedo, traigo dulces para motivarlos, pero tratar de introducirlos al área escolar es difícil. (Participante 4)

\section{El joven en AIJ: visión general}

Según datos de diferentes publicaciones del Center for education, disability and juveniles justice, la mayoría de los jóvenes que ingresan a las instituciones juveniles presentan una serie de necesidades educacionales, sociales, de salud mental y médica. Muchos son marginalmente analfabetos y han confrontado fracaso escolar previo. Predominan los del sexo masculino, socieconómicamente pobres, con problemas significativos de aprendizaje y comportamiento. Ante este hecho global, los entrevistados describieron la tipología de la población que atienden. 
URL: http://www.una.ac.cr/educare

CORREO: educare@una.cr

La mayor parte de los jóvenes que atiendo tienen una edad mayor al grado en que están. Necesitan mucha ayuda individual y por lo regular están poco tiempo con uno, porque de un momento a otro los trasladan a otra institución. Tienen sus días en que están motivados a trabajar. El estado de ánimo de los jóvenes cambia mucho, principalmente cuando regresan de pase o reciben una mala noticia de los familiares. (Participante 1)

He tenido casos que han cometido faltas [graves]: asesinatos, agresión, uso y abuso de drogas. Los jóvenes de antes eran menos agresivos, menos problemáticos que los de hoy. El estado de ánimo de estos jóvenes es variable. (Participante 2)

A ellos no les gusta leer y escribir. Cuando empezamos a ver cambios favorables en ellos los trasladan a otra institución. (Participante 3)

Cada día que pasa es más difícil bregar con la matricula [comparada] con la que teníamos antes. La de [ahora] es más agresiva, problemática, y permanece menos tiempo en la institución. Los que trabajen [aquí] debieran ser especialistas en cada una de las áreas Yo tengo estudiantes de primero a sexto [grado], todo el día. La mayoría tienen una edad mayor al grado que [estudian]. Tengo jóvenes con una edad de 16 años que están en primer grado. (Participante 4)

De acuerdo con C. Alverio (comunicación personal el 26 de septiembre de 2006) y Sauter (2000), en Puerto Rico, los jóvenes institucionalizados se diferencian de sus congéneres delincuentes libres en la comunidad y que asisten a las escuelas públicas. Los institucionalizados pierden la habilidad para integrarse a la sociedad por distintas razones, entre los cuales sobresalen los problemas de salud física y mental, adicción, analfabetismo, falta de destrezas de supervivencia, problemas emocionales, bajo autocontrol, baja autoestima, falta de confianza en ellos mismos, limitaciones en sus destrezas sociales, ninguna esperanza en el futuro, falta de buenos modelos y la falta de dirección.

Además de estas condiciones en la población, se añaden la frustración que experimentan los maestros las conductas difíciles, con cambios de ánimo frecuentes, y ubicados en grados que no concuerdan con su edad cronológica. Se agrava aún más el escenario por el corto tiempo con que cuentan para impactarlos, dada la breve permanencia de estos jóvenes en una institución. Todo esto afecta adversamente la planificación de los servicios educativos, impidiendo responder asertivamente a las necesidades reales.

El joven con problema de salud mental es un gran reto. Se ha estimado que alrededor de un $50 \%$ de los que entran a las instituciones tiene uno o más problemas de salud mental 
(P. Leoni, en comunicación personal el 28 de septiembre de 2006). Sus condiciones les hacen tener comportamientos incontrolables y no manejables, por lo cual terminan encarcelados. Garfinkel (2003) indicó que las facilidades correccionales juveniles han llegado a ser el depósito de jóvenes con serios problemas de salud mental que otras agencias del gobierno no han atendido eficazmente. Por sus condiciones mentales, cometen crímenes que fluctúan entre asesinatos, vandalismo y actividades ilícitas relacionadas con las drogas.

Los jóvenes con problemas mentales referidos al Sistema de Justicia Juvenil regularmente son identificados con desordenes de comportamiento destructor (Rogers, Zima, Powell y Pumariega, 2001). Atender una población de jóvenes encarcelados, en la que la tasa con problemas de salud mental y con comportamiento destructor es alta, requiere de maestros adiestrados en técnicas de manejo de control de grupo (Bennett, 2005). En cuanto a este tema los participantes señalaron lo siguiente.

No se te puede decir absolutamente nada sobre lo que padecen los jóvenes. Uno pregunta y a veces te dicen...Tú desconoces mucho de estos jóvenes. (Participante 1)

Uno tiene que ser sensitivo. Por la experiencia, uno [reconoce] más o menos que joven tiene algún problema de salud mental. En una ocasión tuve uno que quiso hacerse al [instante] un tatuaje con lápiz que le vio a otro compañero. Eso fue muy difícil para mí, ese niño se auto mutiló con un lápiz. Por esa razón el maestro en AIJ debe [ser] capaz para ayudar a los jóvenes de la mejor forma, con el mínimo de información. (Participante 2)

¡Ay Dios mío!, [a veces es difícil] saber qué estudiante tiene problemas de salud mental. En los casos [conocidos] tratamos de informarnos en qué consiste su condición, no vaya a ser que caiga en un error involuntariamente. (Participante 3)

Nosotros no [tenemos información de quién] tiene o no problemas de salud mental, a menos que nos demos cuenta por la observación de la conducta que exhiben. De hecho, hay casos de jóvenes que están ahora mismo con nosotros que tienen situaciones particulares, que tenemos que estar pendiente a modificar conducta, porque se hace difícil controlarlos y atenderlos. Además, mientras trato de atender estas situaciones, tengo al resto de los estudiantes que tienen que cumplir con las tareas diarias ... Cada joven tiene un plan educativo que se tiene que documentar semanalmente. (Participante 4)

La AIJ no provee información referente a los problemas de salud mental de los jóvenes a los maestros por cumplir con la ley de confidencialidad, la Health Insurance Portability 
URL: http://www.una.ac.cr/educare

CORREO: educare@una.cr

and Accountability Act (HIPPA). Los maestros entrevistados indicaron desconocer cuales son los jóvenes con problemas de salud mental y en qué consiste la condición. De conocer algún caso es por su experiencia con esta población o por comentarios informales que han escuchado de otro personal de la institución. Esta situación de desconocimiento afecta el responder adecuadamente la necesidad de los jóvenes. Por otra parte, estas situaciones tienden a agotar físicamente a los maestros, particularmente cuando tienen que individualizar la enseñanza y tratar de cumplir el plan de enseñanza de cada joven; mientras luchan por mantener el orden y el mejor ambiente que requiere todo proceso de enseñanza y aprendizaje.

Estos estudiantes son especiales ... y requieren mucho tiempo; que se les trate con respeto y cariño. (Participante 1)

[Atender a] niños de 17 años que están en un [grado muy por debajo al que corresponde a su edad cronológica] no es fácil. Antes la escolaridad era más baja, pero los jóvenes eran más obedientes. (Participante 2)

He tenido que desarrollar la paciencia con estos jóvenes [se sonrió], de verdad. Un niño de 17 años, en séptimo grado, no es fácil. Tienes que bregar con muchas cosas y [atender] muchos intereses. Además, son muy inquietos ... Un niño de 13 años en un séptimo grado es bien diferente. (Participante 3)

La mayor parte del tiempo me paso llamándoles la atención ... - ¡Mira no hagas eso! ¡Vamos a dar la clase! ¡Estate quieto! No hay motivación, realmente. Se debe diseñar otro currículo para motivar a estos jóvenes. (Participante 4)

Los jóvenes de Educación Especial (EE), con problemas específicos de aprendizaje son frecuentes en la población institucionalizada (Anderson, 2003; Burrell y Warboys, 2000). Según comunicación personal (P. Leoni, 8 de septiembre, 2006) en Estados Unidos existe un alto porcentaje de jóvenes referidos para recibir servicios de EE; en algunas instituciones asciende hasta un $60 \%$ de los casos. La frecuencia de disturbios emocionales, problemas de aprendizaje, retardación mental entre los jóvenes trasgresores es altamente desproporcionada a la frecuencia de los jóvenes no delincuentes. Rutherford, Bullis, Anderson y Griller- Clark (2002) y Harlow (2003) estimaron que entre un $35 \%$ a $42 \%$ de todos los jóvenes y adultos encarcelados tienen condiciones médicas que limitan el aprendizaje. En Puerto Rico, la matrícula de EE alcanza el 60\% (Administración de Instituciones Juveniles, 2007). 
URL: http://www.una.ac.cr/educare CORREO: educare@una.cr

Con los de EE se tiene que ser más flexible. A estos hay que atenderlos individualizados. (Participante 1)

Tenemos mucha matrícula de EE. Dependiendo la necesidad del menor, hay [detalles que acaparan] más atención ... El maestro de EE trata de darle unas destrezas y trabajos adicionales, [ya sea integrados con la población] o lo lleva a su saloncito. (Participante 2)

Trato de poner a trabajar solos a los más adelantados y me voy a atender a aquellos que tienen necesidades [especiales]. [A] esos niños hay que darle [sic] mucha ayuda individualizada. A veces, se nos hace bien cuesta arriba, porque yo tengo unas destrezas que cumplir con los demás. (Participante 3)

Yo diría que bastante de nuestra matrícula es de EE. [Esos] van al salón recurso. Al otro día le repongo el trabajo con acomodo razonable. Con [estos] voy al ritmo que ellos vallan [sic] (Participante 4).

No todo buen maestro puede trabajar exitosamente con estudiantes del Sistema de Justicia Juvenil (Birnbaum, 2001, citado por Bennet, 2005). Proveer servicios educativos a grupos diversos de estudiantes (diferentes niveles educativos y con problemas de aprendizaje) es un gran reto profesional. Ninguno de los participantes entrevistados indicó tener la necesidad de adiestrarse para atender la alta matrícula en EE en sus áreas de trabajo. Sí comentaron haber recibido algún adiestramiento o tomado cursos universitarios sobre este aspecto educativo.

He cogido uno que otro curso de EE que ha ofrecido el DE hace como un año atrás. A mí me interesa aprender. Todo lo que sea para mejorar a mí me interesa. (Participante 1)

En la universidad estuvieron ofreciendo cursos de EE con créditos. He tomado algunos, pero se hace difícil, porque los ofrecen los sábados. (Participante 2)

Cuando estaba en la universidad tome uno que otro curso de EE. Me hubiese gustado tomar los cursos de una propuesta que pagaba la matrícula, pero se me hacía difícil, estos se ofrecían los sábados. (Participante 3) 
URL: http://www.una.ac.cr/educare

CORREO: educare@una.cr

Solo he tomado una que otra orientación de EE que ofrece el [DE]. Me gustaría tomar otros [cursos]. Hace tiempo que no nos ofrecen algún adiestramiento sobre EE. (Participante 4)

Algunos maestros entrevistados indicaron no participar de las reuniones del Comité de Programación y Ubicación (COMPU). Se hace necesario que tanto los educadores de materias como los de educación ocupacional se adiestren continuamente. Los adiestramientos deben ser accesibles en cuanto día, hora y lugar.

\section{El aspecto espiritual del maestro}

La opinión pública considera la educación como una de las profesiones más sacrificadas en el mundo. Jesucristo es un ejemplo de los grandes maestros que han existido. El docente en las correccionales juveniles exhibe aspectos espirituales que les sirven de sustento y para apoyo a los jóvenes.

No me pagan como quisiera, pero esa satisfacción de ser maestro y haber cumplido como ser humano está por encima de cualquier sueldo y más con estos jóvenes. (Participante 1)

Me nace, lo siento en mí, el ser maestro [lo dice llorando]. No sé cómo me sentiré cuando en un momento de mi vida tenga que retirarme. (Participante 2)

Yo soy bien espiritual, y siempre digo que Dios tiene a uno en el lugar donde lo necesita... Para trabajar en este tipo de escenario hay que ser bien especial. (Participante 3)

Yo digo que Dios me tiene aquí con un propósito, porque si fuera otro tipo de persona, creo que hubiera renunciado hace tiempo. (Participante 4)

Se puede inferir que permanecer en este escenario de trabajo por más de 15 años responde al deseo de servir y a un sentido genuino de sacrificio.

Mi primera experiencia fue con jóvenes con impedimentos en el DE. En una ocasión se presentó la oportunidad de trabajar en una institución juvenil y creí que era una oportunidad de ayudar a jóvenes necesitados. (Participantes 1 ) 
Se me hace difícil despegarme de los jóvenes. (Participante 2)

Siento que tengo un deber con estos jóvenes. (Participante 3)

Fui tomada como rehén hace algún tiempo. Dos estudiantes se me tiraron encima y me pusieron una figa [objeto cortante en forma de navaja] en el cuello. Fue un momento difícil ... y estuve unos meses fuera de la institución recibiendo servicios psiquiátricos. Pero, llego un momento que quise volver a la institución y aquí estoy. (Participante 4)

La relación maestro-estudiante es clave en el proceso de enseñanza y aprendizaje. Tan importante como la de un padre y un hijo. En los maestros participantes del estudio se observó un sentido de compromiso con su profesión, el cual va más allá de sus funciones. Fue evidente en ellos una actitud de amor, servicio y sacrificio respecto a estos jóvenes, porque el magisterio para ellos es más que una profesión, es un ministerio.

El maestro es insustituible; ni las computadoras, ni las condiciones externas como tampoco los requisitos de planes detallados que garanticen el aprendizaje pueden sustituir a un buen docente en el salón de clase. El eje fundamental de todo el proceso educativo es la preparación adecuada del maestro. Además de conocer su materia de enseñanza, este debe saber comunicarse con inteligencia emocional con sus estudiantes.

\section{Los logros de los maestros correccionales juveniles}

Los entrevistados indicaron tener logros al igual que sus colegas de cualquier otro sistema educativo. Sin embargo, para ellos estos logros son muy significativos debido a cada condición especial que presenta un joven institucionalizado. Por tanto, cada maestro realiza unos esfuerzos que varían de acuerdo con las complejidades de vida de estos jóvenes (C. Alverio en comunicación personal el 26 de septiembre de 2006).

En una ocasión estaba en un restaurante de comida rápida. De momento, se me acerca un joven y me dijo: - ¿Usted se acuerda de mí? Le dije: — ¡Claro que sí! (aunque realmente no lo recordaba; ellos crecen y cambian muchísimo). El joven me dijo: - Con usted aprendí mucho, hoy día me las busco para vivir, gracias a lo que aprendí en su clase. Para mí eso fue grandioso. Estoy consciente de que devengo un sueldo como maestro ... Pero esos comentarios, me causan mucha satisfacción. (Participante 1) 
URL: http://www.una.ac.cr/educare

CORREO: educare@una.cr

Atiendo jóvenes al nivel elemental, es decir de primer a sexto grado. En ocasiones he tenido estudiantes de 14 años o más que no saben leer o leen muy lento. Mi mayor logro es ver que aprendieron a leer o escucharlos que leen más rápido. Estas experiencias me hacen sentir muy feliz. (Participante 2)

La experiencia de trabajar en instituciones juveniles ha sido fuerte. Cada día que llegas a la institución [entras con] la expectativa de qué pasará. Esa situación crea cierta tensión. Sin embargo, ... tengo muchas experiencias positivas. Algunas...han sido en el mismo salón, cuando se logra el dominio de una destreza o uno ve algún cambio de conductas. También he tenido la experiencia de que me reconozcan en la calle o en las tiendas. De esa forma me entero que están vivos y algunos de ellos trabajando. Eso me llena de satisfacción, porque sé que al recordarme, quizás lo que le enseñé les ayudó. (Participante 3)

Los jóvenes que ingresan a la institución son más agresivos que los de hace 10 o 15 años atrás. Pero, tengo que decir que esta situación se convierte en un reto y eso me gusta. Me siento capaz de continuar trabajado en la institución y eso me llena de mucha satisfacción. Verdaderamente me nace ayudar a estos jóvenes. Mi mayor logro profesional ha sido el servir a esta población. (Participante 4)

Las experiencias vividas por los maestros en AIJ son únicas e irrepetibles. Tras una mirada detallada de esas experiencias se percibe que el maestro está comprometido con los jóvenes más allá de su deber magisterial. Sin embargo, existe la necesidad de establecer programas de adiestramientos a estos maestros para que respondan de una forma más adecuada y pertinente ante las necesidades educativas de estos jóvenes. Por último, de acuerdo con la información provista por los participantes de este estudio, es imperativo que las agencias gubernamentales se unan y propongan algún modelo educativo innovador que responda a una educación liberadora tanto para los estudiantes como para los maestros.

\section{Conclusiones}

La AIJ tiene por mandato de ley ofrecer servicios educativos a los jóvenes que están bajo la custodia del Estado. El currículo que se utiliza es el mismo que se ofrece en las escuelas públicas del país, centros educativos de los cuales la mayoría de los jóvenes desertaron, por lo que estos no les eran atractivos. Por otro lado, se percibe a través de las respuestas de los participantes una ausencia en coordinación de servicios educativos y el equipo multidisciplinario para atender los aspectos cognitivos y emocionales de los jóvenes. La preparación del maestro de AIJ es la misma que recibe los maestros de los otros sistemas educativos del país. Todo lo anterior afecta el proceso de enseñanza y aprendizaje. 
Los maestros se sienten frustrados por la falta de motivación de estos jóvenes, quienes presentan comportamientos variables y poco interés en las actividades del proceso de enseñanza y aprendizaje. Sin embargo, afirmaron tener logros y satisfacciones que los fortalecen espiritualmente, haciendo que permanezcan muchos años en las instituciones juveniles.

La información recibida al comenzar a trabajar en la correccional sobre el escenario de trabajo y la clientela a ser atendida fue mínima. Por otra parte, estos educadores carecen de representación por una organización profesional especializada en instituciones correccionales.

Los cursos de educación ocupacional resultan más atractivos para los jóvenes que los cursos académicos. La alta gerencia de la AIJ parece tener más interés en el control y la seguridad del ambiente institucional que en el desarrollo profesional de sus maestros y en el aprovechamiento educativo de estos jóvenes.

\section{Recomendaciones}

Dada la naturaleza de este estudio, sus propósitos, la bibliografía revisada, los hallazgos e interpretación de la experiencia recopilada se formularon las siguientes recomendaciones. Estas están orientadas hacia la labor o responsabilidad que deben tener tanto la AIJ y como el DEPR, las universidades y los maestros de las instituciones correccionales.

\section{Administración de Instituciones Juveniles en conjunto con el Departamento de Educación}

- La preparación académica de los docentes debe incluir cursos relacionados con el manejo asertivo de esta población y otros aspectos tales como: a) principios de psicología básica, b) técnicas de control de grupos, c) alternativas motivacionales que vayan a tono con teorías pedagógicas efectivas. También, cursos de educación preocupacional y ocupacional que respondan a los intereses reales de los jóvenes institucionalizados.

- Adoptar métodos de enseñanza diferentes y revisar el contenido de los currículos para ajustarlos a las necesidades personales y sociales de los jóvenes trasgresores. Por ejemplo, establecer alianzas colaborativas con las escuelas cercanas a las instituciones para que los jóvenes puedan participar de otros ofrecimientos académicos innovadores.

- Incluir cursos de educación preocupacional y ocupacional que respondan a los intereses reales de los jóvenes institucionalizados.

- Establecer alianzas colaborativas para que los jóvenes puedan participar de cursos avanzados de educación ocupacional o proyectos especiales que ofrezcan las escuelas cercanas a las instituciones juveniles. 
URL: http://www.una.ac.cr/educare

CORREO: educare@una.cr

- Desarrollar un programa de orientación inicial y un manual de normas generales que tienen que ser observadas por todo personal adscrito al programa educativo de la AIJ, que incluya aspectos gerenciales como empleado y aspectos administrativos del salón de clases.

- Adiestrar a docentes sobre el manejo de conductas difíciles o disfuncionales.

- Tanto la AIJ como el DE deben proveer los materiales didácticos necesarios para desarrollar las materias que se enseñan. Estos materiales tienen que ser seguros, según las normas de seguridad, y servir para desarrollar las múltiples inteligencias.

- Asimismo, proveer los periódicos nacionales y otros medios escritos con el fin de desarrollar las destrezas morales y de ser humano completo, según lo proponen Bandura (1976), Freire (1987) y De Hostos (1969).

- Adiestrar a los docentes sobre la preparación de currículos que respondan a las necesidades reales de los jóvenes institucionalizados.

- Proveerles actividades de desarrollo profesional a tono con las nuevas tendencias de la educación en general en específic a lo referente a la educación correccional.

- Incluir a los maestros de AIJ en la participación y beneficios de la Ley de Carrera Magisterial.

- Ofrecer un incentivo económico a aquellos maestros que desarrollen estrategias educativas eficaces e innovadoras que mejoren las actividades educativas en su institución. Se debe estimular la investigación en acción, en la que el maestro y los jóvenes se involucren, de tal manera que estas estrategias educativas puedan ser aplicadas en otras instituciones.

- Promover encuentros profesionales a nivel local, nacional e internacional entre maestros de las instituciones juveniles para compartir sus estrategias pedagógicas y los hallazgos de las investigaciones que hayan realizado.

- Establecer normas y procesos que faciliten la colaboración de profesionales distinguidos en distintas áreas para que compartan sus experiencias de triunfo y destrezas para alcanzar el éxito.

- Establecer espacios de tiempo para reuniones de equipos interdisciplinarios.

- Incluir en el equipo interdisciplinario la participación de un consejero en rehabilitación para que maneje los aspectos de limitaciones funcionales y capacidad funcional que crean los diferentes impedimentos en estos jóvenes.

- Establecer como requisito de trabajo, para los maestros que deseen trabajar en AIJ, cursos en educación especial o especialidades afines. 
- Hacer cumplir la participación de los maestros de la AIJ en la preparación del Programa de Educativo Individualizado (PEI) de los jóvenes, según lo establecen los Manuales de Normas y Procedimientos basados en la Ley Publica 105-17 IDEA (junio, 1997).

- La AlJ debe velar por el acondicionamiento adecuado de las salas de clases. Estas deben ser seguras según las normas institucionales y estar preparadas según las pautas pedagógicas de cada materia. Además, estos espacios deberán estar bien iluminados, con asientos y mesas de trabajo apropiadas, y que la temperatura disminuya la fatiga por calor.

La educación es una etapa de transición entre el individuo y su identidad social. Por tanto, se hace imperativo proponer un modelo integral que se base en la enseñanza comprensiva, integradora, unificada y diversificada a través del aprendizaje significativo para el aprendiz. Este modelo debe contemplar al docente como un eje fundamental en el proceso de rehabilitación. Por esto, un modelo educativo para estos jóvenes debe contener lo siguiente:

Un currículo orientado a desarrollar en los individuos el manejo de sus emociones, para que adquieran aquellas herramientas necesarias para vivir adecuadamente y puedan asumir un rol social responsable. Por tanto, el proceso educativo debe organizarse en orden lógico y psicológico, con el esfuerzo dirigido a educar la razón y que no se límite únicamente al cultivo del conocimiento; debe desarrollar el uso de la sensibilidad y de la voluntad. Además, este debe tener en cuenta los aspectos correccionales en su redefinición de metas y objetivos a tono con la globalización. Estos modelos de concienciación y del desarrollo de la razón, la moral y el hombre completo tienen sus bases en el humanismo, fundamentado en la realidad. La metodología debe responder a las necesidades educativas de los jóvenes transgresores. Además, se sugiere trabajar en el desarrollo de mecanismos que promuevan la concienciación, el compartir de experiencias, recursos y destrezas entre todos los maestros del sistema correccional.

Como referente, el maestro de mayor experiencia debe servir de mentor de los maestros de nuevo ingreso. Estos maestros deben creer en el poder transformador de la enseñanza y deben estar adiestrados en técnicas y estrategias de enseñanzas no tradicionales que sean útiles para este escenario educativo. Por ejemplo, deben saber sobre el manejo de conductas difíciles y del coraje, educación especial y principios básicos de psicología. Además, la filosofía educativa de la educación correccional debe estar adaptada a nuestra cultura puertorriqueña.

Los directores escolares deben desarrollar estrategias administrativas donde los maestros en correccionales puedan compartir con otros compañeros de su misma materia para intercambiar ideas, información de cómo realizar la tarea de forma más efectiva y, más que nada, el cómo mantenerlos motivados de manera que se sientan valorados por sus contribuciones. Realmente es necesario e importante que se dedique tiempo al desarrollo de relaciones humanas y las áreas afectivas. 
URL: http://www.una.ac.cr/educare

CORREO: educare@una.cr

En la realidad educativa de las correccionales juveniles no todo es válido, tampoco todo es equivocado. Se hace necesario conocer diferentes teorías y disponer de diversas experiencias educativas para poder adaptarlas a las necesidades reales de cada institución. Teorías como las múltiples inteligencias de Gardner y la inteligencia emocional de Goleman, son de suma utilidad poder identificar las capacidades en los estudiantes, y de esa forma delinear las actividades más apropiadas para obtener el máximo aprovechamiento. Hay que insistir, para que esto ocurra el docente debe recibir la debida capacitación profesional, disponer de tiempo adicional para su desarrollo, institucionalizar el trabajo y recibir el apoyo de la alta gerencia.

Las universidades deben establecer acuerdos colaborativos entre todas facultades de educación y de ciencias de la conducta para ofrecer cursos electivos en educación de confinados. De este esfuerzo, deben desarrollar un programa conducente a un grado en educación con especialidad en instituciones correccionales. Estos acuerdos colaborativos deben ofrecer una práctica o internado en las instituciones correccionales.

Los maestros de instituciones correccionales deben fomentar la creación de una organización profesional que les agrupe y los represente.

\section{Limitaciones del estudio}

Este estudio se limitó a cuatro maestros de 10 años o más de experiencia en AIJ. Se recomienda realizar otros estudios más abarcadores para auscultar las experiencias y necesidades estos educadores. Por ejemplo, se debe profundizar sobre los retos y las necesidades de desarrollo profesional. Por otra parte, algunos maestros fueron muy cautelosos al proveer información porque entendían que podrían ser identificados. Esto pudo limitar el contenido de otra información valiosa en cuanto a las experiencias vividas, los retos y las necesidades específicas de estos educadores.

\section{Referencias}

Administración de Instituciones Juveniles. (2007). Informe estadístico: Programa de servicios educativos y recreativos. San Juan, Puerto Rico.

Anderson, C. L. (2003). Characteristics of Juvenile Court: Correction Teachers and Job Satisfaction. [Características de la Corte Juvenil: Maestros de corrección y satisfacción en el empleo]. (Tesis doctoral inédita). University of Southern California, California EE.UU.

Bandura, A. (1976). Teoría del aprendizaje social. Madrid: Espasa-Calpe.

Bennet, J. (2005). Juvenile's Correctional Education: A Case Study of Correctional Classroom Management [Educación correccional de menores: Un estudio de caso de manejo del aula correccional] (Tesis doctoral inédita). University of Idaho, Idaho EE.UU. 
Black, T. H., Brush, M. M., Grow, T. S., Hawes, J. H., Henry, D. S. \&, Hinkle, R. W. Jr. (1996). Natural Bridge Transition Program Follow-up Study. [Estudio de seguimiento del programa de transición de enlace natura]. Journal of Correctional Education, 47(1), 4-12.

Bruner, J. (2001). The culture of Education. [La cultura de la educación]. Cambridge: Harvard University Press.

Burrell, S., \& Warboys, L. M. (julio, 2000). Special education and the juvenile justice system. [La educación especial y el sistema de justicia juvenil]. US Department of Justice, Office of Justice Programs, Office of Juvenile Justice and Delinquency Prevention (pp. 1-15). Recuperado de http://www.criminologycenter.fsu.edu/p/nationalDataClearinghouse/ Publications\%20Reports/OJJDP\%20Special\%20Ed.pdf

Carr, B. A. (2001). Behind the Fences: a Phenomenological Study of the Lived Experience of a Prison Classroom Teacher [Detrás de las rejas: Un estudio fenomenológico de la experiencia vivida por el maestro de corrección]. (Tesis doctoral inédita). Texas Tech University, Texas, Estados Unidos.

Creswell, J. W. (1994). Research Design: Qualitative \& Quantitative Approaches. [Diseño de investigación: enfoques cuantitativos y cualitativos]. California: Sage Publication.

Dean, V. J. (2005). The Experience of Receiving Special Education Services in a Juvenile Detention Facility [La experiencia de recibir servicios de educación especial en un centro de detención juvenil]. (Tesis doctoral inédita). Michigan State University, Department of Educational Administration, Michigan, Estados Unidos.

De Hostos, E. M. (1969). Obras completas de Eugenio Maria de Hostos (Vol. 23), San Juan, Puerto Rico: Editorial Coqui.

Drucker, P. F. (1993). Management: Task Responsibilities and Practices. [Administración: Tareas, responsabilidades y prácticas]. Boston: Harper \& Row.

Eggleston,C.R.(1991). Correctional Education Professional Development. [Desarrollo profesional de la educación correccional]. Journal of Coorrectional Education, 42(1), 174-181.

Foley, R. M. (2001). Academic Characteristics of Incarcerated youth and Correctional Educational Programs. [Características académicas de jóvenes encarcelados y los programas de educación correccional]. Journal of Emotional \& Behavioral Disorder, 9(4), 248-259. doi: $1063-4266$

Freire, P. (1987). Pedagogía del oprimido (27ª ed.). México: Siglo XXI.

Garfinkel, L. (marzo, 2003). Parents: Supporting Parents of Youth with Mental Health Problems. [Padres: Padres que apoyan a jóvenes con problemas de salud mental]. EDJJ Notes, 2(3), 5-7.

Gehring, T., \& Hollingsworth (2002). Coping and Beyond: Practical Suggestions for Correctional Educators. [El manejo y más allá: sugerencias prácticas para educadores correccionales]. Journal of Correctional Educational, 53(3), 89-95. 
URL: http://www.una.ac.cr/educare

CORREO: educare@una.cr

Gehring, T., \& Puffer, M. (2005). Integral Correctional Education: Three Explanatory Essays. [Educación correccional integral: Tres ensayos explicativos]. Manuscrito inédito, Center for the Study of Correctional, California State University, California.

Geraci, P. (2002). Teaching on the Inside: A Survival Handbook for the New Correctional Educator. [Educando desde el interior: Manual de supervivencia para el nuevo educador correccional]. Minnesota: Greystone Educational Materials.

Goleman, D. (2000). La inteligencia emocional. México: Vergara.

Harlow, C. W. (enero, 2003). Education and correctional populations. [La educación y la población correccional]. NCJ 195670. Washington, DC: US Department of Justice, Office of Justice Programs.

Jandt, F. E. (2004). An Introduction to Intercultural Communication: Identities in a Global Community. [Una introducción a la comunicación intercultural: Identidades en una comunidad global] (4 $4^{\mathrm{a}}$ ed.). California: SAGE.

Jurich, S., Casper, M., \& Hull, K. A. (2001). Training Correctional Educators: A Needs Assessment Study. [Capacitación de los educadores correccionales: Un estudio de necesidades]. Journal of Correctional Education, 52(1), 23-27.

Ley Núm. 68 del 28 de agosto de 1990. Ley Orgánica del Departamento de Educación del Estado Libre Asociado de Puerto Rico. Efectiva el 28 de agosto de 1990, según enmendada (3 L.P.R.A. sec. 391 y ss).

Lucca, N., \& Berríos, R. (2003). Investigación cualitativa en educación y ciencias sociales. San Juan: Publicaciones Puertorriqueñas.

Price, T. C. (1996). Correctional Education at a Crossroads. [Encrucijadas de la educación correccional]. Journal of Correctional Education, 47(3), 116-117.

Ragland, B. B. (2005). Razor Wire Cuts Both Ways: Teaching Inside a Juvenile Institution. [EI alambre de púas corta de dos maneras: Enseñanza dentro de una institución juvenil]. (Tesis doctoral inédita). University of Tennessee, Knoxville EE.UU.

Ramos, l., \& Bravo, M. (2002). Prácticas para facilitar el desarrollo profesional en las escuelas de Puerto Rico: Encuesta a educadores. Pedagogía, 36, 93-125.

Rivera, P. (2004). Bases educativas para la renovación curricular en la escuela puertorriqueña. El Sol, 3, 5-8.

Rogers, K. M., Zima, B., Powel, E., \& Pumariega, A. J. (2001). Who is Referred to Mental Health Services in the Juvenile's Justice System? [¿Quién es referido a los servicios de salud mental en el sistema juvenil de justicia?]. Journal of Child and Family Studies, 10(4), 485494. 
URL: http://www.una.ac.cr/educare CORREO: educare@una.cr

Rosado, M. (2001). Percepciones que tienen los maestros de educación especial sobre el desarrollo y los planes de mejoramiento profesional. (Tesis doctoral inédita). Universidad Interamericana de Puerto Rico, Recinto Metropolitano, San Juan.

Rutherford, R. B., Bullis, M., Anderson, C. W., \& Griller-Clark, H. M. (2002). Youth With Disabilities in theCorrectional System:PrevalenceRatesand Identification Issues. [Jóvenes discapacitados en el sistema de corrección: Tasa de prevalencia y aspectos de identificación]. (Monograph Series on Education). Disability and Juvenile Justice. (ED471213).

Sauter R. E. (2000). A Study to Identify the Special Concerns and Curricular Needs of the Professional Correctional Educator of Youthful Ofenders. [Un estudio para identificar las inquietudes especiales y las necesidades curriculares del educador correccional profesional de ofensores juveniles] (Tesis doctoral inédita). California: Pepperdine University.

Sayko, E. Á. (2005). The Making of a Prison Teacher: A Phenomenological Journey Through Lived Experiences of Correctional Educators. [La construcción de un maestro de prisión: Una travesía fenomenológica a través de la experiencia vivida por los educadores correccionales]. (Tesis doctoral inédita). Maryland: University of Maryland, College Park.

Weis, M. P, Haynes, N., \& Lloyd, J. W. (2001). Detention Home Teachers in Virginia: Who Are They and What is Their Job Like. [Los maestros de un hogar de detención en Virginia: Quiénes son y cómo es su trabajo]. Journal of Correctional Education, 52(3), 99-104.

Wolford, B. I. (2000). Youth Education in the Juvenile Justice System. [La educación de menores en el sistema juvenil de justicia]. Correction Today, 62(5), 126-130.

Wright, R. (2005). Going to Teach in Prisons: Culture Shock [Voy a enseñar en prisiones: El impacto cultural]. The Journal of Correctional Education, 56(1), 19-38.

\section{Cómo citar este artículo en APA:}

Santa, A, Villafañe, Á A., \& Capella, M. Educadores en instituciones correccionales para jóvenes en Puerto Rico: Retos y necesidades de desarrollo profesional. Revista Electrónica Educare, 18(1), 7-39. Recuperado de http://www.revistas.una.ac.cr/index.php/EDUCARE/issue/current

Nota: Para citar este artículo en otros sistemas puede consultar el hipervínculo "Como citar el artículo" en la barra derecha de nuestro sitio web:

http://www.revistas.una.ac.cr/index.php/EDUCARE/index 